\title{
Numerical and experimental study of variation in mechanical properties of epoxy hybrid laminates due to change in orientation
}

\author{
Pranali Kajale \\ ${ }^{*}$ Department of mechanical Engineering, Sinhagad College of Engineering (SCoE), Pune
}

DOI: 10.29322/IJSRP.11.09.2021.p11742

http://dx.doi.org/10.29322/IJSRP.11.09.2021.p11742

\begin{abstract}
In the present work, the effect of orientation on tensile and flexural properties of symmetric angle-ply laminate is studied. Five types of carbon fiber and E-glass fiber hybrid laminates are considered viz. $[0 / \pm 15] 2 \mathrm{~s},[0 / \pm 30] 2 \mathrm{~s},[0 / \pm 45] 2 \mathrm{~s},[0 / \pm 60] 2 \mathrm{~s},[0 / \pm 75] 2 \mathrm{~s}$ with constant overall fiber volume fraction and stacking sequence of all the composites. For numerical study purpose, a code is developed in MATLAB based on classical lamination theory; including Tsai-Wu failure criterion for first-ply failure (FPF). To validate the numerical results, layups of all five types are tested under uniaxial and buckling loads as per ASTM D-3039 and ASTM D-790 standards respectively. Maximum tensile and flexural strength of $346.67 \mathrm{MPa}$ and $135.49 \mathrm{MPa}$ is obtained for [0/ \pm 15$] 2 \mathrm{~s}$ types of laminate. Results obtained from experimentation shows good agreement with numerical results having mean absolute relative error (MARD) of $9.24 \%$ in tensile test and $7.52 \%$ in flexural test.
\end{abstract}

Index Terms- Hybrid composites, angle-ply laminate, Classical laminate theory, Tsai-wu failure criteria, mechanical properties

\section{INTRODUCTION}

$\mathrm{I}^{\mathrm{n}}$ the recent days, the usage of composite materials in industries like automobile, aircraft and marine is increasing because of their advantages over conventional materials. Composites offer high strength and stiffness as compared with conventional material containing same amount of mass. Currently a lot of research is going in the field of hybrid laminates where two or more materials are used as reinforcement in the matrix. The main objective of hybrid laminate is to obtain the optimum properties by using the different fibers. However, due to the anisotropic nature of composite materials, it is highly unpredictable to determine the properties of them. There have been extensive studies on developing and determining critical tensile and bucking load of carbon/glass fiber reinforced composite laminate. Jesthi and Nayak[1], have studied the effects of stacking sequence on mechanical properties of epoxy hybrid composite laminates. Yuan et al.[2], have investigated the tensile strength and failure modes of thin ply carbon fiber-reinforced polymer (CFRP) angle-ply laminates. Caminero et al.[3], have studied tensile and flexural strengths of symmetric angle-ply CFRP laminates. Almeida Jr et al.[4], have studied effect of fiber orientation on shear strength of glass fiber-reinforced polymer (GFRP). Heidari-Rarani et al.[5], have examined effects of stacking sequence on buckling behavior of GFRP.

This paper attempts to analyze the effect of orientation on mechanical properties of epoxy hybrid composite laminates. In this paper, numerical and experimental study is performed for the analysis of glass and carbon fiber hybrid laminate. Five symmetric angle-ply laminates $[0 / \pm 15] 2 \mathrm{~s},[0 / \pm 30] 2 \mathrm{~s},[0 / \pm 45] 2 \mathrm{~s},[0 / \pm 60] 2 \mathrm{~s},[0 / \pm 75] 2 \mathrm{~s}$ were selected. Properties like thickness of plies and fiber volume fraction were maintained constant in all five laminates. For numerical analysis, MATLAB code is used based on classical laminate theory (CLT); along with Tsai-Wu failure criteria for first-ply failure analysis. The results obtained from numerical analysis are further validated through experimentation. 


\section{LAMINATE DESIGN}

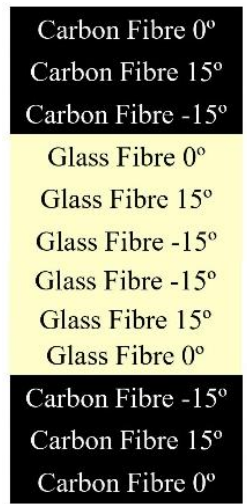

(a) $[0 / \pm 15]_{2 \mathrm{~s}}$

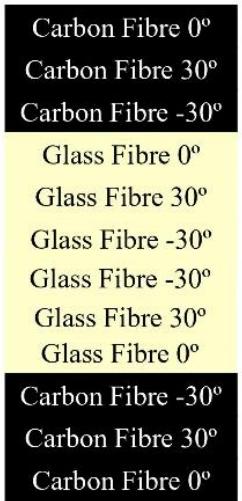

(b) $[0 / \pm 30]_{2 \mathrm{~s}}$

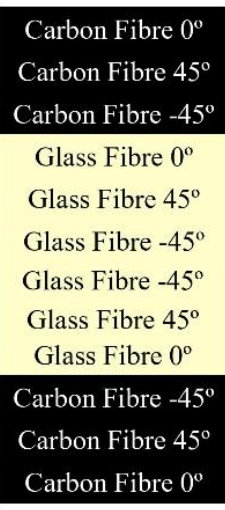

(c) $[0 / \pm 45]_{2 \mathrm{~s}}$

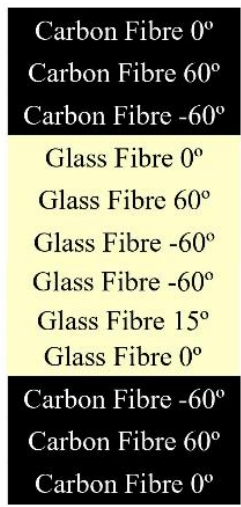

(d) $[0 / \pm 60]_{2 \mathrm{~s}}$

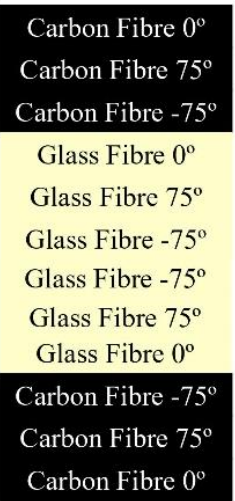

(e) $[0 / \pm 75]_{2 \mathrm{~s}}$

Figure 1 Stacking sequence of composite laminates

Unidirectional carbon fiber (200 GSM) and E-glass fiber (260 GSM) were selected for reinforcement with matrix as epoxy resin (Resin: Araldite LY 5052, Hardener: Aradur 5052). Even though carbon fiber is known for its high strength and stiffness, its cost is not affordable for many applications. Whereas, glass fiber has reasonable cost with moderate strength and stiffness. Hence, a hybrid composite of carbon fiber and glass fiber is tried to develop for obtaining high strength at affordable cost. Generally, the stacking sequence of laminated plates is designed to be symmetric and balanced to avoid unpredictable warp deflections. Hence the specimens are selected as $[0 / \pm \alpha] 2 \mathrm{~s}$ combination with a change of angle by $15^{\circ}$ and maintaining overall volume fraction. Studies have shown that laminates with carbon fiber positioned at exterior regions provides higher tensile and flexural strength [6]. So top and bottom three stacks are decided to be of carbon fiber/epoxy material (see Figure 1). A uniform thickness of $0.25 \mathrm{~mm}$ is maintained for each layer, which gives the total thickness of laminates manufactured around $3.0 \pm 0.1 \mathrm{~mm}$.

\section{NUMERICAL PROCEDURE}

$\begin{array}{lll}\mathrm{E} & = & \text { Elastic modulus } \\ \mathrm{V} & = & \text { Volume fraction } \\ \mathrm{v} & = & \text { Poisson's ratio } \\ \mathrm{G} & = & \text { Shear modulus } \\ \mathrm{Q}_{\mathrm{ij}} & = & \text { Coefficient of reduced stiffness matrix in material direction } \\ \mathrm{Q}_{\mathrm{ij}}^{\prime} & = & \text { Coefficient of reduced stiffness matrix off its material direction } \\ \mathrm{A}_{\mathrm{ij}} & = & \text { Coefficient of in-plane stiffness matrix } \\ \mathrm{B}_{\mathrm{ij}} & = & \text { Coefficient of coupling matrix } \\ \mathrm{D}_{\mathrm{ij}} & = & \text { Coefficient of flexural stiffness matrix } \\ \text { Subscripts } & \\ f, m \quad= & \text { fibre and matrix } \\ L, T & = & \text { Longitudinal and Transverse direction } \\ s, c & = & \text { Sine and Cosine }\end{array}$




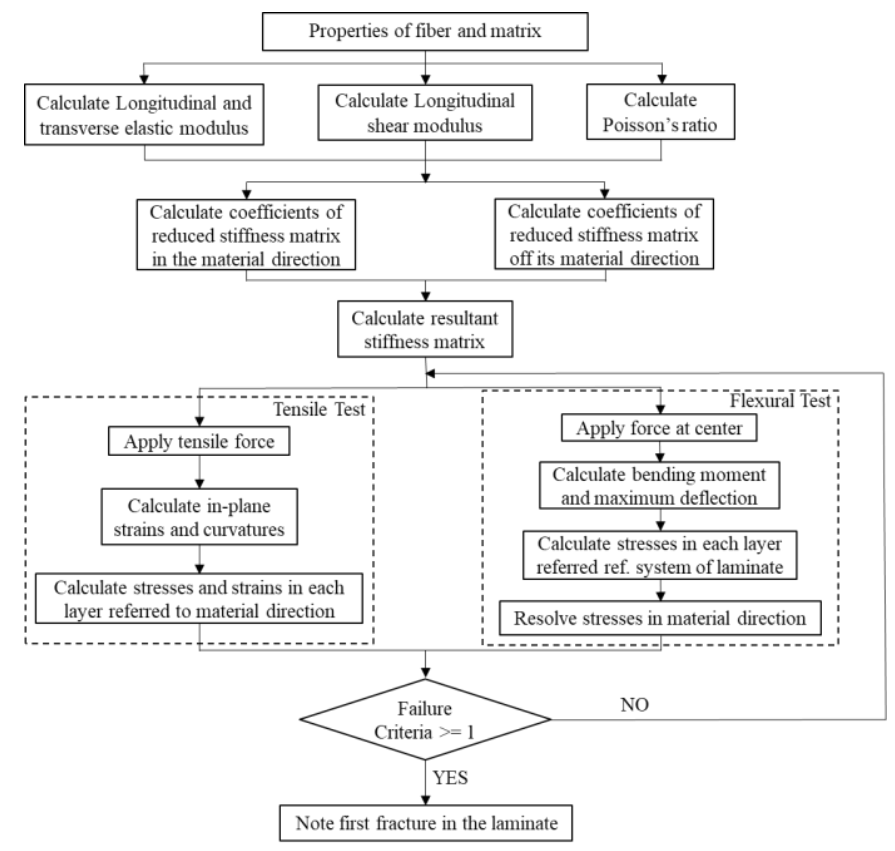

Figure 2 Flow chart for numerical calculations

Classical laminate theory (CLT) with Tsai-Wu failure criteria is used to perform numerical analysis. Figure 2 shows the flow chart of numerical procedure used to determine first fracture in laminate.

\section{A. Equations:}
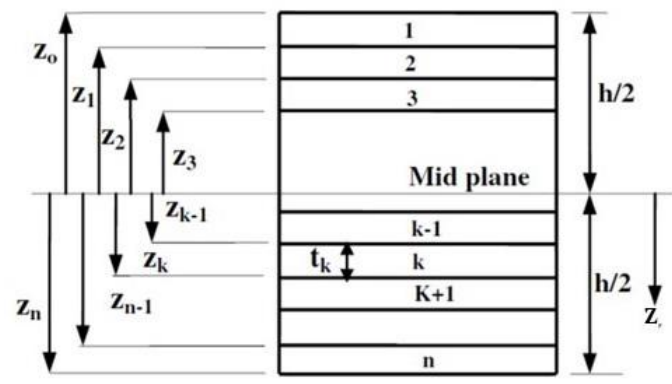

Figure 3 Coordinate locations of plies in a laminate

Longitudinal and transverse elastic modulus:

$$
\begin{gathered}
E_{L}=E_{f} V_{f}+E_{m} V_{m} \\
\frac{1}{E_{T}}=\frac{V_{f}}{E_{f}}+\frac{V_{m}}{E_{m}}
\end{gathered}
$$

Poisson's ratio and longitudinal shear modulus:

$$
\begin{gathered}
v_{L T}=v_{f} V_{f}+v_{m} V_{m} \\
G_{L T}=G_{m} \frac{G_{f}\left(1+V_{f}\right)+G_{m}\left(1-V_{f}\right)}{G_{f}\left(1-V_{f}\right)+G_{m}\left(1+V_{f}\right)}
\end{gathered}
$$

The coefficients of reduced stiffness matrix in the material direction:

$$
\begin{gathered}
Q_{11}=\frac{E_{L}}{1-v_{L T}^{2} \frac{E_{T}}{E_{L}}}, \quad Q_{12}=\frac{E_{T}}{1-v_{L T}^{2} \frac{E_{T}}{E_{L}}}, \quad Q_{22}=\frac{v_{L T} E_{T}}{1-v_{L T}^{2} \frac{E_{T}}{E_{L}}}, \\
Q_{66}=G_{L T}, \quad Q_{16}=Q_{26}=0
\end{gathered}
$$

Also, coefficients of reduced stiffness matrix off its material direction: 


$$
\begin{aligned}
& Q_{11}^{\prime}=Q_{11} c^{4}+2\left(Q_{12}+2 Q_{66}\right) s^{2} c^{2}+Q_{22} s^{4} \\
& Q_{12}^{\prime}=\left(Q_{11}+Q_{22}-4 Q_{66}\right) s^{2} c^{2}+Q_{12}\left(s^{4}+c^{4}\right) \\
& Q_{16}^{\prime}=\left(Q_{11}-Q_{12}-2 Q_{66}\right) s c^{3}+\left(Q_{12}-Q_{22}+2 Q_{66}\right) s^{3} c \\
& Q_{22}^{\prime}=Q_{11} s^{4}+2\left(Q_{12}+2 Q_{66}\right) s^{2} c^{2}+Q_{22} c^{4} \\
& Q_{26}^{\prime}=\left(Q_{11}-Q_{12}-2 Q_{66}\right) s^{3} c+\left(Q_{12}-Q_{22}+2 Q_{66}\right) s c^{3} \\
& Q_{66}^{\prime}=\left(Q_{11}+2\left(Q_{12}+2 Q_{66}\right)+Q_{22}\right) s^{2} c^{2}+Q_{66}\left(s^{4}+c^{4}\right)
\end{aligned}
$$

Resultant ABD stiffness matrix:

$$
\left[\begin{array}{c}
N_{x} \\
N_{y} \\
N_{x y} \\
M_{x} \\
M_{Y} \\
M_{x y}
\end{array}\right]=\left[\begin{array}{llllll}
A_{11} & A_{12} & A_{16} & B_{11} & B_{12} & B_{16} \\
A_{12} & A_{22} & A_{26} & B_{12} & B_{22} & B_{26} \\
A_{16} & A_{26} & A_{66} & B_{16} & B_{26} & B_{66} \\
B_{11} & B_{12} & B_{16} & D_{11} & D_{12} & D_{16} \\
B_{12} & B_{22} & B_{26} & D_{12} & D_{22} & D_{26} \\
B_{16} & B_{26} & B_{66} & D_{16} & D_{26} & D_{66}
\end{array}\right]\left[\begin{array}{c}
\varepsilon_{x x}^{0} \\
\varepsilon_{y y}^{0} \\
\gamma_{x y}^{0} \\
k_{x} \\
k_{y} \\
k_{x y}
\end{array}\right]
$$

Where $[A],[B]$ and [D] are in-plane stiffness matrix, coupling matrix and flexural stiffness matrix. The values of $A_{i j}$, $B_{i j}$, $D_{i j}$ are given as:

$$
\begin{gathered}
A_{i j}=\sum_{k=1}^{n}\left(Q_{i j}^{\prime}\right)_{k}\left(z_{k}-z_{k-1}\right) \\
B_{i j}=\sum_{k=1}^{n}\left(Q_{i j}^{\prime}\right)_{k}\left(z_{k}^{2}-z_{k-1}^{2}\right), \quad D_{i j}=\sum_{k=1}^{n}\left(Q_{i j}^{\prime}\right)_{k}\left(z_{k}^{3}-z_{k-1}^{3}\right)
\end{gathered}
$$

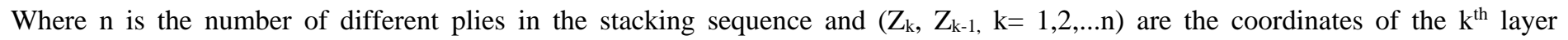
boundaries measured from the middle surface as shown in Figure 3.

\section{B. Tensile stresses and strains}

The loads are applied to a structure constituted of a laminated material are such that $\mathrm{N}_{\mathrm{x}}$ is tensile load per unit width of laminate and $\mathrm{N}_{\mathrm{y}}, \mathrm{N}_{\mathrm{xy}}$ are considered as zero. Using equation (7), values of in-plane strains $\left(\varepsilon_{x x}^{0}, \varepsilon_{y y}^{0}, \gamma_{x y}^{0}\right)$ and curvatures $\left(k_{x}, k_{y}, k_{x y}\right)$ are obtained. Stresses in each layer $\mathrm{k}$, referred to the material directions of the layer, are calculated from equation:

$$
\left[\begin{array}{c}
\sigma_{L} \\
\sigma_{T} \\
\sigma_{L T}
\end{array}\right]_{k}=\left[\begin{array}{ccc}
c^{2} & s^{2} & s c \\
s^{2} & c^{2} & -s c \\
-2 s c & 2 s c & c^{2}-s^{2}
\end{array}\right]\left[\begin{array}{ccc}
Q_{11}^{\prime} & Q_{12}^{\prime} & Q_{16}^{\prime} \\
Q_{12}^{\prime} & Q_{22}^{\prime} & Q_{26}^{\prime} \\
Q_{16}^{\prime} & Q_{26}^{\prime} & Q_{66}^{\prime}
\end{array}\right]\left[\begin{array}{c}
\varepsilon_{x x}^{0} \\
\varepsilon_{y y}^{0} \\
\gamma_{x y}^{0}
\end{array}\right]+\left[\begin{array}{ccc}
c^{2} & s^{2} & s c \\
s^{2} & c^{2} & -s c \\
-2 s c & 2 s c & c^{2}-s^{2}
\end{array}\right]\left[\begin{array}{lll}
Q_{11}^{\prime} & Q_{12}^{\prime} & Q_{16}^{\prime} \\
Q_{12}^{\prime} & Q_{22}^{\prime} & Q_{26}^{\prime} \\
Q_{16}^{\prime} & Q_{26}^{\prime} & Q_{66}^{\prime}
\end{array}\right]\left[\begin{array}{c}
k_{x} \\
k_{y} \\
k_{x y}
\end{array}\right] z_{z}
$$

\section{Three-point bending stress and strains}

In case of three-point bending beam, it is assumed that two end points are simply supported and the force P is applied at the center. The bending moment can be expressed as:

$$
M=\frac{-P L}{2}
$$

The maximum deflection at the center of the beam can be obtained using formula:

$$
w_{c}=\frac{P L^{3}}{48 b D_{11}^{*}}
$$

Stresses in each layer $\mathrm{k}$, referred to the reference system of laminate, are calculated from equation:

$$
\begin{aligned}
\sigma_{x x}^{k} & =-3 a_{x x}^{k} \frac{P L}{b h^{3}} z \\
\sigma_{y y}^{k} & =-3 a_{y y}^{k} \frac{P L}{b h^{3}} z \\
\sigma_{x y}^{k} & =-3 a_{x y}^{k} \frac{P L}{b h^{3}} z
\end{aligned}
$$

With 


$$
\begin{aligned}
& a_{x x}^{k}=\left(Q_{11}^{k} D_{11}^{*}+Q_{12}^{k} D_{12}^{*}+Q_{16}^{k} D_{16}^{*}\right) \frac{h^{3}}{12} \\
& a_{y y}^{k}=\left(Q_{12}^{k} D_{11}^{*}+Q_{22}^{k} D_{12}^{*}+Q_{26}^{k} D_{16}^{*}\right) \frac{h^{3}}{12} \\
& a_{x y}^{k}=\left(Q_{16}^{k} D_{11}^{*}+Q_{26}^{k} D_{12}^{*}+Q_{6}^{k} D_{16}^{*}\right) \frac{h^{3}}{12}
\end{aligned}
$$

Where, $D_{i j}^{*}$ are the coefficients of inverse of matrix [D]. Further, stresses are resolved to the material direction of each layer as:

$$
\left[\begin{array}{c}
\sigma_{L} \\
\sigma_{T} \\
\sigma_{L T}
\end{array}\right]_{k}=\left[\begin{array}{ccc}
c^{2} & s^{2} & s c \\
s^{2} & c^{2} & -s c \\
-2 s c & 2 s c & c^{2}-s^{2}
\end{array}\right]\left[\begin{array}{l}
\sigma_{x x} \\
\sigma_{y y} \\
\sigma_{x y}
\end{array}\right]_{k}
$$

\section{Failure criteria}

Tsai-Wu criteria is used for failure analysis due to its simple form and high prediction accuracy. In case of material subjected to plane stresses in plane $(L, T)$, this criterion is expressed as:

$$
F_{1} \sigma_{L}+F_{2} \sigma_{T}+F_{11} \sigma_{L}^{2}+F_{22} \sigma_{T}^{2}+F_{66} \sigma_{L T}^{2}+2 F_{12} \sigma_{L} \sigma_{T} \leq 1
$$

The coefficients $F_{i}$ and $F_{i j}$ are expressed in terms of strength of composite materials as;

$$
\begin{gathered}
F_{1}=\frac{1}{X_{t}}+\frac{1}{X_{c}}, F_{2}=\frac{1}{Y_{t}}+\frac{1}{Y_{c}}, F_{11}=-\frac{1}{X_{t} X_{c}} \\
F_{22}=-\frac{1}{Y_{t} Y_{c}}, F_{66}=\frac{1}{S_{L T}^{2}}, F_{12}=-\frac{1}{2} \sqrt{F_{11} F_{22}}
\end{gathered}
$$

Whear $\mathrm{X}_{\mathrm{t}}$ and $\mathrm{X}_{\mathrm{c}}$ are tensile and compressive strengths in direction of fibers, $\mathrm{Y}_{\mathrm{t}}$ and $\mathrm{Y}_{\mathrm{c}}$ are tensile and compressive strengths in perpendicular direction to the fibers and $S_{\mathrm{LT}}$ is shear strength. Hence, the first fracture in the laminate is evaluated by applying this failure criteria to each layer.

\section{EXPERIMENTATION}

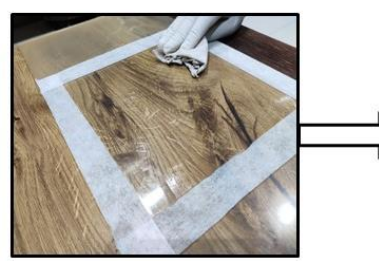

Preparation of mold

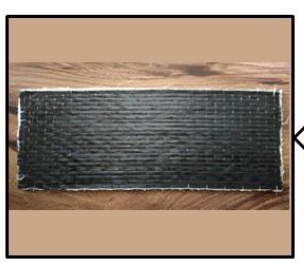

Final Hybrid Composite Laminate

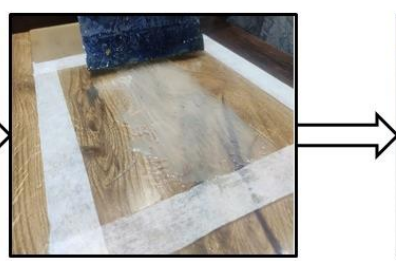

Application of Matrix

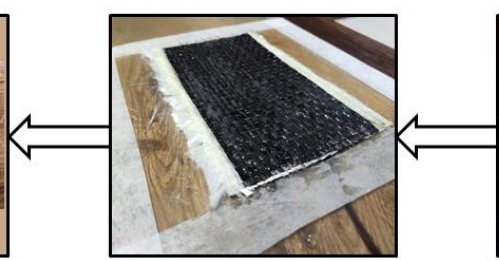

Laminate ready for Curing

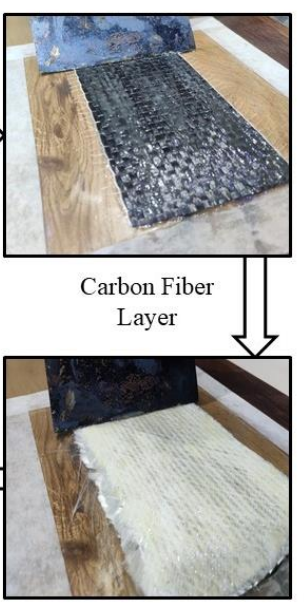

Glass Fiber Layer

Figure 4 layup of composite laminate

Composite laminates were manufactured using wet layup method. Araldite LY 5052 as a resin and Aradur 5052 as a hardener is mixed in ratio 3:1 by weight to create a homogeneous mixture of matrix. Matrix quantity was measured and then applied to each layer for maintaining the overall volume fraction. An open mold is created by applying a releasing agent on the glass surface which will help to separate laminate from the base. The fabrication process starts with applying a thin layer of matrix on an open mold. Dry fabric is placed on it and again a matrix layer is applied. Similarly, subsequent layers of fibers were incrusted as per the predefined stacking sequence. The laminates were kept at room temperature for 7 days to cure. After 7 days of curing, laminates were separated from glass surface and prepared for particular testing. Figure 4 shows the schematic of different steps followed during fabrication. 
Tensile tests of laminates were conducted as per ASTM D-3039 with sample size of $250 \mathrm{~mm} \times 25 \mathrm{~mm} \times 3 \mathrm{~mm}$. For each laminate, results were obtained in the form of tensile stress, tensile strain and modulus. Similarly, for flexural test, ASTM D-790 standards were used with sample size of $100 \mathrm{~mm} \times 10 \mathrm{~mm} \times 3 \mathrm{~mm}$. In this case, results were obtained in the form of flexural strength.

\section{RESULT AND DISCUSSION}

\section{A. Error Analysis}

An error analysis is performed to compare numerical results with experimental values. Mean absolute relative error (MARD) is calculated to analyse errors in the numerical values using following formula:

$$
M A R D=\frac{100}{N} \sum_{i=1}^{N}\left|\frac{\text { Predicted }_{i}-\text { Experimental }_{i}}{\text { Experimental }_{i}}\right|
$$

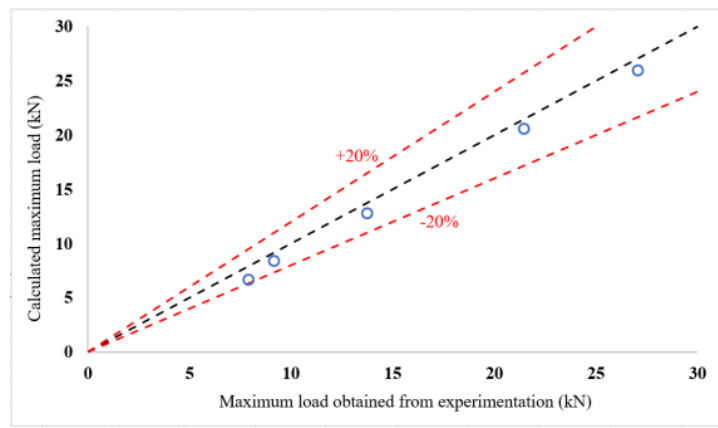

A

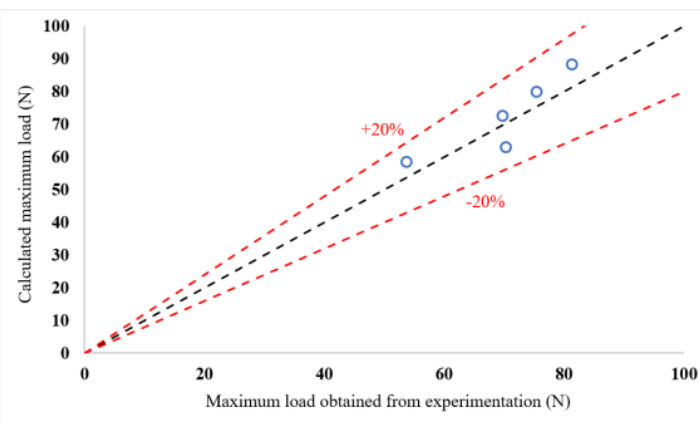

B

Figure 5 Comparison of numerical and experimental results A. Tensile Test B. Flexural Test

The MARD value for maximum tensile load is $9.24 \%$ and that for maximum flexural load is $7.52 \%$. Figure 5 shows that the numerical values of maximum tensile and flexural load are in line with that reported experimentally with less than $20 \%$ error. This confirms that classical laminate theory (CLT); along with Tsai-Wu failure criteria can be used as a successful approach to determine laminate failure.

\section{B. Tensile strength}

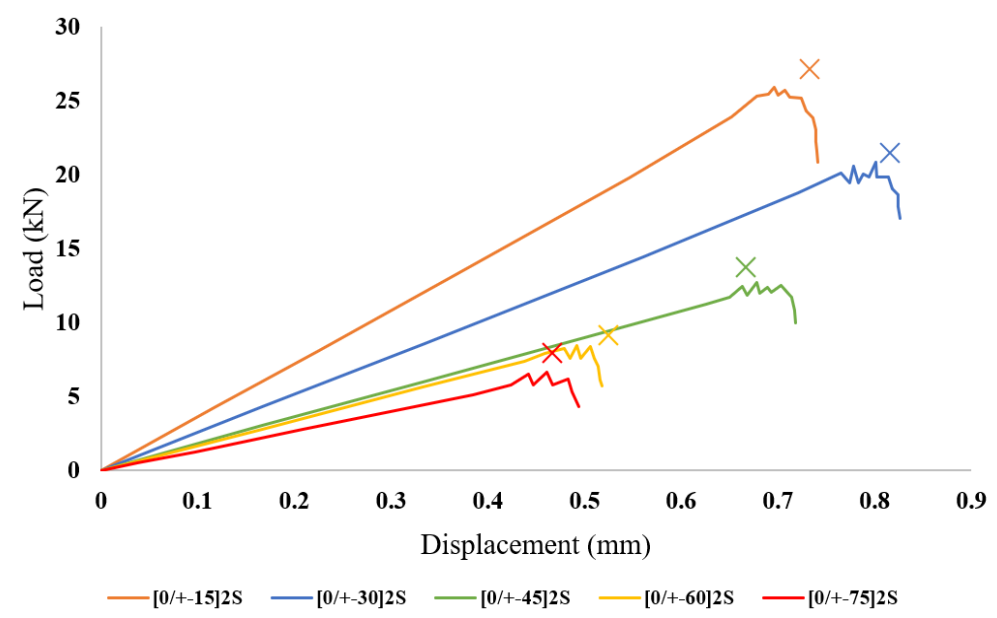

Figure 6 Graph of Tensile Load-displacement

Tensile test was conducted for the hybrid composite laminates and force-displacement curves obtained are presented in Figure 6. The crosses marked in figure represent values of maximum loads and displacements of laminates before failure obtained numerically. The tensile properties like tensile strength, tensile strain and modulus of the laminates are given in Table 1 . It can be observed from the table that the $[0 / \pm 15]_{2 \mathrm{~s}}$ laminate showed highest tensile strength, tensile strain of $346.67 \mathrm{MPa}$ and $1.46 \%$ respectively whereas lowest tensile strength, tensile strain of $88.26 \mathrm{MPa}$ and $0.987 \%$ is showed by $[0 / \pm 75]_{2 \mathrm{~s}}$ laminate. Variation in the strength of laminates is mainly due to the change in angles of layers. Strength of laminates decreases with increase in the angle. Also, a small step is observed in between initial linear part and failure in the Error! Reference source not found.. The initial drop may be due to failure of glass 
fiber layers followed by immediate drop due to failure of carbon fiber layers. A similar type of observation is reported in Nagaraja et al.[6], while determining the suitable stacking sequence for glass and carbon fiber hybrid composite.

Table 1 Tensile and flexural properties of composite laminates

\begin{tabular}{|l|c|c|c|c|c|}
\hline$[0 / \pm 15]_{2 \mathrm{~s}}$ & Tensile strength (MPa) & Tensile strain (\%) & Flexural strength (MPa) & Tensile failure & Flexural failure \\
\hline$[0 / \pm 30]_{2 \mathrm{~s}}$ & 346.67 & 1.46 & 135.49 & & \\
\hline $0 / \pm 45]_{2 \mathrm{~s}}$ & 278.04 & 1.65 & 89.58 & & \\
\hline$[0 / \pm 60]_{2 \mathrm{~s}}$ & 166.67 & 1.43 & 117.27 & \\
\hline$[0 / \pm 75]_{2 \mathrm{~s}}$ & 88.26 & 1.03 & 116.36 & \\
\hline
\end{tabular}

\section{Flexural strength}

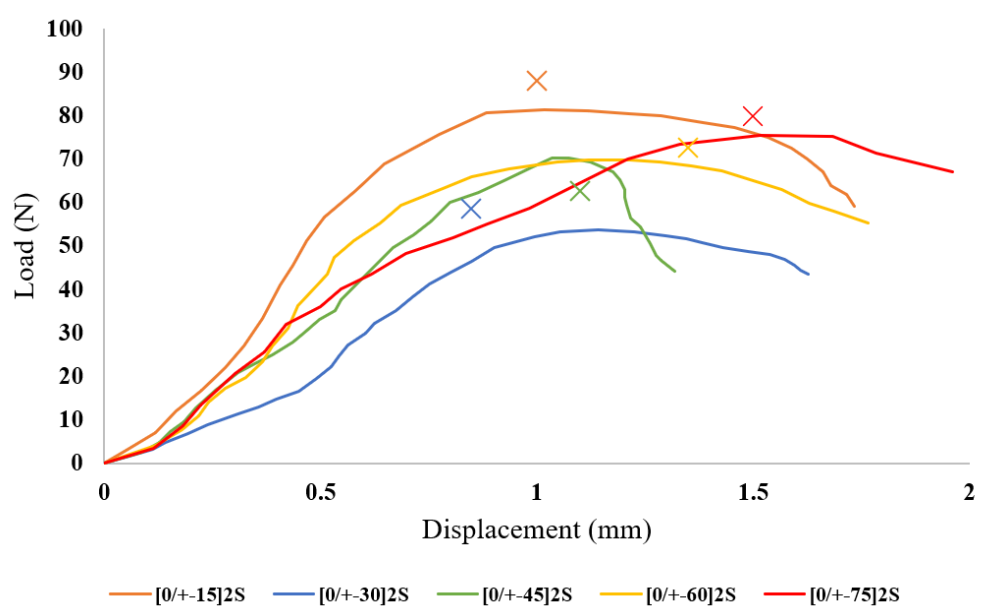

Figure 7 Graph of Flexural Load-displacement

Flexural test was conducted for all the hybrid composite laminates and force-displacement curves obtained are presented in Figure 7. Flexural strengths of laminates are noted in Table 1 . From table it can be seen that the $[0 / \pm 15]_{2 \mathrm{~s}}$ laminate possess highest flexural strength of $135.49 \mathrm{MPa}$. The results obtained in current study are different from one reported by Heidari-Rarani et al.[5], where it is concluded that by increasing the angle from $0^{\circ}$ to $90^{\circ}$ in $[ \pm \theta]_{\mathrm{s}}$ laminate, the critical buckling load decreases continuously. The difference between results is mainly due to addition of $0^{\circ}$ layers in external region. Bending load is mostly taken by the external layers of the composite laminate as compared to that interior region. As exterior regions have $0^{\circ}$ layers, the change in angle of internal layers is not affecting the flexural strength drastically. However, it can be concluded from the figure that $[0 / \pm 45]_{2 \mathrm{~s}}$ laminate have least deformation before failure as compared to other laminates.

\section{CONCLUSION}

The effect of orientation of $[0 / \pm \theta]_{2 s}$ hybrid laminates on tensile and flexural properties of is studied numerically and experimentally.

- The numerical values obtained from classical laminate theory (CLT); along with Tsai-Wu failure criteria are in line with that reported experimentally. While comparing numerical results with experimental values, mean absolute relative error (MARD) of $9.24 \%$ is calculated in tensile test whereas $7.52 \%$ is estimated in flexural test. 
- In $[0 / \pm \theta]_{2 s}$ laminate tensile strength, tensile strain and modulus values decrease with increase in the values of $\theta$ from $15^{\circ}$ to $75^{\circ}$.

- In case of flexural strength, the change in $\theta$ is not affecting the flexural strength considerably. However, it can be concluded from the figure that $[0 / \pm 45]_{2 \mathrm{~s}}$ laminate have least deformation before failure as compared to other laminates.

\section{REFERENCES}

[1] Jesthi, D.K., Nayak, R.K., "Evaluation of mechanical properties and morphology of seawater aged carbon and glass fibre reinforced polymer hybrid composites," Composites Part B: Engineering, 174: 106980, 2019, doi: 10.1016/j.compositesb.2019.106980.

[2] Yuan, Y., et al., "Failure modes and strength prediction of thin ply CFRP angle-ply laminates," Composite Structures, 176: 729-735, 2017, doi: 10.1016/j.compstruct.2017.06.005.

[3] Caminero, M.A., et al., "Tensile and flexural damage response of symmetric angle-ply carbon fibre-reinforced epoxy laminates: Non-linear response and effects of thickness and ply-stacking sequence," Polymer Composites, 40(9): 3678-3690, 2019, doi: 10.1002/pc.25230.

[4] Almeida Jr, J.H.S., et al., "Effect of fibre orientation on the shear behaviour of glass fibre/epoxy composites," Materials \& Design (1980-2015), 65: 789-795, 2015, doi: 10.1016/j.matdes.2014.10.003.

[5] Heidari-Rarani, M., et al., "Effect of ply stacking sequence on buckling behaviour of E-glass/epoxy laminated composites," Computational Materials Science, 89: 89-96, 2014, doi: 10.1016/j.commatsci.2014.03.017.

[6] Nagaraja, K., et al., "Studying the effect of different carbon and glass fabric stacking sequence on mechanical properties of epoxy hybrid composite laminates," Composites Communications, 21: 100425, 2020, doi: 10.1016/j.coco.2020.100425.

\section{AUTHORS}

First Author - Pranali Kajale, B.E. Mechanical, Sinhgad College of Engineering, Pune, kajalepranali@gmail.com

Correspondence Author - Pranali Kajale, kajalepranali@gmail.com, 8698121144 